\title{
DossIÊ
}

ENSino E Pesquisa em HistóRia ANTiga e História Medieval no Brasil

\section{APRESENTAÇÃO UM MERGULHO NA HISTÓRIA ANTIGA E NA HISTÓRIA MEDIEVAL}

A História Antiga e a História Medieval vieram para ficar. No Brasil, esses campos expandiramse significativamente nas últimas três décadas, marcando presença em revistas especializadas, dossiês, livros autorais, coletâneas de artigos e em eventos acadêmicos de toda sorte. A História Antiga, legatária ou não das perspectivas marxistas, weberianas ou da Escola de Cambridge, conquistou espaços na universidade brasileiras e, como apontaram Margarida Maria de Carvalho e Pedro Paulo A. Funari, "os investigadores antiquistas escolherão seus métodos, técnicas e teorias de abordagem, associando tais interpretações à análise iconográfica e à cultura material" (CARVALHO; FUNARI, 2007, p. 15). A História Medieval, vinculou-se às três gerações da Escola dos Annales, estruturalistas ou não, assumindo escolhas semelhantes à História Antiga, e constituiu-se igualmente como uma espécie de manancial inesgotável de temas, métodos e abordagens teóricas, cuja capacidade é testar as identidades e alteridades com o passado, que ultrapassam a crença nas perspectivas temporais continuístas e baseadas em noções problemáticas tais como origem, sobrevivência, reminiscências ou herança (BASTOS, RUST, 2008, p. 187-188; SILVA, 2004, p. 87-107).

A História Antiga e a História Medieval possuem um passado recente de desenvolvimento comum no Brasil. Inicialmente presentes nas universidades do sudeste e sul, passaram pouco a pouco a figurar em centros universitários do Nordeste, Centro-Oeste e Norte, acompanhando o processo de expansão universitária das últimas décadas. Em grande medida, são áreas historiográficas irmãs, porque lidam com abordagens, métodos e técnicas adaptadas às características espaço-temporais de tempos remotos. Elas lidam com conhecimentos especializados de línguas antigas e medievais (demótico, aramaico, sânscrito, grego, latim e, para a Idade Média, as línguas vernaculares), mas também línguas contemporâneas como espanhol, inglês, francês, italiano e alemão, o que os tornam campos que nasceram vinculadas a sua vocação internacional. Essas áreas dialogam com outras campos das Ciências Humanas, assumem a multiplicidade de temporalidades e ritmos e, por fim, enfrentam a valorização dos contextos de produção e apropriação dos documentos quase sempre escassos e dependentes de metodologias qualitativas. Ambos os campos são legatários da Nouvelle Histoire das três gerações da 
Escola dos Annales, da História Cultural, como alternativa à História das Mentalidades, seguindo escalas de perspectivas pós-modernas, ou visões dinâmicas mais realistas críticas de um marxismo renovado.

Contudo, não obstante a expansão significativa, elas ainda enfrentam o desafio de contribuir a seu modo para o reforço e renovação das Ciências Humanas e do próprio campo da História. Ambas não são entidades monolíticas, sem tensões e articulações internas, e, por isso mesmo, estão relacionadas às distintas correntes epistemológicas, universos teórico-conceituais, metodologias adaptadas às especificidades documentais e à História da Historiografia. Ainda vigora a atitude de que esses dois campos historiográficos não deveriam ocupar a vida acadêmica universitária ou adentrar as tecituras do cotidiano de um país que não teve um mundo antigo reminiscente ou um medievo geográfico.

A cibercultura, as multimídias contemporâneas ou as "guerras de narrativas" no ensino de História, como diria Christian Laville (1999), estão aí para desmentir quaisquer descasos com o campo do conhecimento historiográfico, dando legitimidade e importância para que não negligencie nenhuma temporalidade e suas (re)apropriações extemporâneas. Os quatro artigos desse dossiê colocam frações espaço-temporais em foco e o fazem a partir de perspectivas distintas. Todavia, apesar das diferenças que os tornam únicos, os autores procuram abordar suas respectivas bases documentais conectando-as à vida material e às representações, aos discursos e contextos históricos mais amplos, às subjetividades e objetividades, dando dimensão histórica às concepções de tempo, pessoas, instituições, relações sociais e às espacialidades, evitando binarismos epistemológicos estanques.

Comecemos pelas espacialidades. As cidades não são neutras ou simples espaços físicogeográficos sem historicidade. Elas também são configurações materiais profundamente articuladas com condições sociais, políticas, jurídicas e simbólicas de um determinado tempo. Este é o pressuposto analítico assumido pelo artigo de Macsuelber de Cássio Barros da Cunha, doutor em História pela Universidade Federal de Goiás. Ele versa sobre as construções materiais e simbólicas de Roma como capital do mundo conhecido no período augustano. Embora utilize subsidiariamente a numismática, a autoria reúne sobretudo numerosas referências sobre a fundação mítica da capital do Império, sem deixar de relacioná-la aos processos de desenvolvimento arquitetônico. Percorrendo as penas de Títo Lívio, Virgílio, Dionísio de Halicarnasso, Suetônio, Cícero, Vitrúvio, Estrabão, Pausânias, Plínio, entre outras referências, Cunha discute a força gravitacional que o centro de poder romano produziu não somente no imaginário religioso-sagrado como também nas circunscrições jurídicas e nas estratégias de legitimação e propaganda políticas.

Palácios, templos, prédios públicos, teatros, anfiteatros, fóruns, banhos, piscinas, canais, aquedutos, estradas e estátuas, sistema de drenagens e esgoto, tudo isso fazia parte tanto da arquitetura política quano simbólica de Roma, misturando funções sociais, religiosas, ideológicas e materiais. Associada ao mito fundador dos augúrios vistos por Rômulo e Remo, dos voos dos abutres à lendária materna da loba que os amamentou, Roma também estava associa às deusas Vitória e Magna Mater. Como disse o autor, "a cidade era o suporte sobre o qual se erigiam expressivos complexos arquitetônicos, que além de servir às funções religiosas, políticas, de sociabilidade, etc., serviam também 
como uma importante ferramenta política nas mãos de Augusto." E complementa: “por meio do melhoramento arquitetônico de Roma ele demonstrava o seu cuidado e interesse nas relações com as divindades, bem como com a vida dos cidadãos e habitantes de Roma, que passaram a viver numa cidade cada vez mais monumental e rica, devido ao influxo de riquezas advindas de outras partes do Império." Todos os autores estudados por Barros da Cunha fizeram coincidir a geografia simbólica, sagrada, mítica e fundacional aos propósitos da geografia política augustana. Entre o simbólico e o material, a Urbs era parte inseparável de imagens, imaginários e das formas estratégicas de exercício do poder manifesto nas e pelas espacialidades.

Roma também era um centro de estudos tanto quando um ponto axial do Império, tornandose, junto com outros centros, como Alexandria, um espaço de produção de uma cultura literária relativamente ampla para os padrões antigos. O que significa dizer que, além das bibliotecas domésticas, havia possibilidade de circulação limitada, porém mais ampla do que se imagina, ultrapassando as cátedras intelectuais por meio de compras, empréstimos e cópias de livros. Há historicidade nas relações entre poesia e ensino, entre a arte de escrever e as dimensões pedagógicas. O texto de Rodrigo Santos Monteiro Oliveira, mestre em História pela Universidade Federal de Goiás, é um esforço bem sucedido de discutir sobre a concepção da missão de ensinar presente na poesia didática das obras De rerum natura e Astronomicas, respectivamente, de autoria de Lucrécio e Manílio, entre os séculos I a.c. e I d.c. Em termos teóricos e metodológicos, Oliveira lança mão das teorias da recepção e da comparação para discutir os caminhos das relações entre ensino e aprendizagem.

Por um lado, ele relativiza a aplicabilidade das concepções de leitor ideal, discutindo o alcance e a presença dialógica e interlocutória dos leitores implícitos ou extratextuais idealizados nos escritos dos dois autores antigos. Ao discorrer sobre as relações entre professor e aluno no contexto literário da poesia didática na Antiguidade, Rodrigo Oliveira compara os escritos de Lucrécio e Manílio, identificando as semelhanças e diferenças, aproximações e distanciamentos, convergências e divergências entre eles e com outros autores tais como Cícero, Horácio, Petrónio, Quintiliano, Virgílio, Catão Censor, Varrão, Diomedes, entre outros. Vale destacar que as abordagens de Lucrécio e Manílio aos seus alunos não constituem-se apenas de semelhanças no que tange à questão do equilíbrio entre o deleite e as obrigações dos estudos, da brevidade e adequação das palavras do docente frente aos discentes, e os destinatários das elites romanas. Basendo-se em Matt Neuburg, Oliveira percebeu algumas diferenças entre os dois autores antigos. Enquanto Manílio encorajaria permanentemente "seu aluno a partir de um esforço necessário para o sucesso, Lucrécio anteciparia os erros, cansaços e distrações de Mêmio [seu interlocutor retórico], exortando-o mais do que encorajando-o", apesar de "os tratamentos realizados" se enquadrarem "na elaboração da constelação professor-aluno, característica essencial do gênero poético didático."

Apesar de Lucrécio ter identificado seu interlocutor discente, algo que não havia feito Manílio, que o deixa claro por meio de marcadores textuais e retóricos indiretos, ambos visavam fazer propaganda da legitimidade e centralidade das atividades docentes com vista a alcançar um público mais amplo do 
que as elites romanas. Daí as táticas de envolver os alunos, a dialogicidade, mesclando o apelo ao deleite e prazer de aprender e ensinar nos caminhos tortuosos da compreensão e busca pelo saber. Para o autor Rodrigo Santos Monteiro, a bela missão de ensinar presente nas obras poéticas didáticas não pode ser enquadrada em modelos fechados, pois não havia limites estilísticos rígidos para os romanos que desejassem escrever. O que implica dizer que, ao se discutir sobre o gênero didático na Antiguidade romana, seria necessário analisar as obras lucreciana e maniliana a partir de teorias e metodologias flexíveis e compatíveis com aos interesses e tipos de conhecimentos forjados pela cultura escrita da época.

O contexto da retórica escrita e a orientação dos ouvintes e leitores potenciais também foram uma preocupação de Raimundo Moura, mestre em História pela Universidade Federal de Goiás, cujo artigo se dedica a estudar a hagiografia de São Goderico e a interação santa com os animais de Finchale, no Norte da Anglia, nos séculos XI e XII. Trata-se de um estudo das mensagens morais e do imaginário social presentes da obra a Vida de São Goderico (VSG), que foi escrita pelo monge beneditivo Reginaldo de Durham, no final do século XII, na qual ele relata os contatos do mercador asceta com alguns animais tais como as serpentes, um lobo e um cervo. A obra deve ser circunscrita em um contexto de defesa de bens, de terras e do patrimônio sagrado do priorado de Durham, como as relíquias e os santuários. A VSG cumpria um papel propagandístico frente às pressões impetradas pelas autoridades locais, seculares ou eclesiásticas, na comunidade monástica.

Diante disso, o autor pondera que as relações entre santidade e os animais têm raízes antigas, especialmente bíblicas e patrísticas, sendo que o medievo difundiu e alterou as mensagens edificantes por meio especialmente dos bestiários e das hagiografias. O autor incorpora uma metodologia sensível às especificidades narrativas e tipológicas das vidas de santos e santas, e das influências das culturas populares nas narrativas hagiográficas sobre os animais. Raimundo Moura ainda destaca que a adaptação dos temas dos animais à ótica cristã, sem deixar de sinalizar as tensões entre magia e religião, entre práticas heterodoxas ou ortodoxas do cristianismo, foi uma dimensão importante para que se transmitisse as mensagens morais como estratégia para alcançar uma coletividade mais ampla.

Desta forma, as narrativas hagiográficas revelam conteúdos simbólicos que encarnam a interação ou a reciprocidade entre santos e animais de formas bastante dinâmicas, representando os animais no Medievo não somente como sinais da providência divina, como também manifestação de forças ou ações diabólicas. Como diz o autor, "havia uma dimensão simbólica, cujos significados estavam conectados às concepções religiosas que a sociedade reclamava para si." Comparando com outras hagiografias, tais como as de São Martinho de Tours, de Santo Antão, de São Cuteberto e de Santa Wereburga, Moura argumenta que a VSG também usa como metáfora a obediência dos animais ao santo, como seres irracionais, contrastando com os comportamentos humanos, cuja desobediência a Deus teria ocorrido em tempos edênicos. Por exemplo, as serpentes mostraram-se mansas, não apresentando nenhum sinal de perigo, embora continuassem sendo vistas como animais peçonhentos e perigosos. Na lógica da narrativa hagiográfica, as criaturas selvagens tiveram suas características predatórias subtraídas pela 
companhia do asceta escolhido de Deus. O lobo, embora estivesse associado ao Diabo, fora submetido pelo santo, servindo de representação de como a santidade e o poder de Deus submete o mal e o expulsa. O caso de um cervo, que fugia dos caçadores e foi protegido pelo santo, é a síntese da proteção sagrada do santo e do ente divino.

Os animais não são vistos como intrínseca e absolutamente bons ou maus, mas eventualmente serviam para enfatizar o heroísmo do hagiografado por meio do domínio sobre os animais, como foi dado ao primeiro "homem" antes do pecado original. O santo seria o reconstrutor das condições da vida antes da Queda concretizadas através da sua dedicação à reclusão ascética e, em último instância, da obediência aos desígnios de Deus. No fundo a interação entre o santo e os animais teria uma relação de semelhança com o comportamento humano, "uma metáfora para as virtudes que deveriam ser cultivadas pelos mortais.” A obediência animal dos tempos edénicos é atualizada pela narrativa sobre o santo. Seus atos serviriam de modelo exemplar para a obediência humana. Como diz o autor, "os eventos hagiográficos serviram como instrumentos para inculcar valores, como a ideia de que a proteção milagrosa deveria ser acompanhada pela humildade."

Por fim, Edilson Menezes, mestre e doutorando em História pela Universidade Federal Fluminense, dedica um artigo ao tema dos poderes aristocráticos com base nos cartulários da chancelaria régia da monarquia francesa nos séculos XII e XIII, em especial os atos de chancelaria de Filipe Augusto. Por um lado, o autor discute a problemática das dinâmicas das elações de dominação da aristocracia feudal frente às comunidades camponesas. Por outro, seguindo uma perspectiva marxista, portanto, abordando o assunto a partir da perspectiva epistemológica realista crítica, o objetivo do texto é analisar a "interrelação entre a aparência fenomênica da documentação requisitada e as dinâmicas sócio metabólicas que essa aparência pode velar, a sistematicidade oculta da dominação social sobre as comunidades rurais." Rompendo com as visões excessivamente culturalistas e fenomênicas, que enfatizam um valor quase autônomo aos discursos e representações, Menezes complexifica as relações histórico-filosóficas entre aparência e essência, forma e conteúdo, discursos e práticas, representações e factualidades, subjetividades e objetividades, as dimensões fenomênicas aparentes e a síntese da totalidade historiográfica.

Combinando análises qualitativas e quantitativas sobre os cartulários, que foram organizados em compêndios por influência da ascensão nacionalista da História francesa no século XIX, o autor rompe com a mea culpa da historiografia francesa contemporânea que não enfrentaria o problema da reprodução e contestação da dominação de grupos aristocráticos entre si por meio da expropriação do trabalho camponês. No lugar de aceitar um campesinato mudo ou secundarizado, negligenciando a sua agência histórica nas relações de poder, ele propõe uma História Política sensível à análise sistemática das interações, tesões, conflitos e fraturas entre grupos aristocráticos, mas também os acordos, compromissos e negociações estabelecidas nos processos de composição e recomposição de grupos senhoriais e monárquicos, sem deixar de vincular tudo isso à dialética das dinâmicas de produção rural. 
Para Edson Menezes, os grupos aristocráticos e os senhorios não eram homogêneos e desprovidos de frações de classes, disputas internas ou acordos mútuos. Fundamentando suas análises nas reflexões de Karl Marx, Georg Lukács, Fabrice Mouthon, Mário Jorge da Motta Bastos, Reinaldo Carcanholo e João Bernardo, entre outras referências, ele discute as comunidades rurais como pontos axiais de articulações e tensionamentos da composição e recomposição das aristocracias feudais. Com intuito de superar a aparência ou excesso de empiria dos fenômenos históricos, a autoria procura compreender e explicar a interrelação mútua entre os grupos. De um sujeito não manifesto ou oculto à presença, da aparência à essência, da análise desses casos particulares ao vislumbre de uma totalidade histórica, eis a proposta do autor: um mergulho teórico-filosófico, documental e historiográfico sobre a produção e reprodução da vida material e a apropriação do trabalho alheio que condicionam a estruturação da sociedade. Afinal, como destaca o Edson Menezes, "Nem tudo que parece é."

Segundo Walter Benjamin, em um texto chamado Sobre o conceito de história, o ato de articular historicamente o passado não significa conhecê-lo à moda positivista e historicista como ele foi de fato (BENJAMIN, 1995, p. 224). Significa, diz o autor, "apropriar-se de uma reminiscência, tal como ela relampeja no momento de um perigo." E segue num tom esperançoso do papel dos historiadores: "O dom de despertar no passado as centelhas da esperança é privilégio exclusivo do historiador convencido de que também os mortos não estarão em segurança se o inimigo vencer. E esse inimigo não tem cessado de vencer" (BENJAMIN, 1995, p. 224-225). Walter Benjamin escrevia em 1940, em tom masculino (o "historiador") e posicionava-se política e intelectualmente diante dos fascismos europeus. Hoje, em tempos de negacionismos, guerras de narrativas e flertes com autoritarismos, o ofício de historiadores e historiadoras constitui uma vereda importante no processo de crítica das cumplicidades historiográficas.

Embora situados em universos temáticos, historiográficos e teórico-epistemológicos bastante distintos, os quatro artigos desse dossiê ajudam a desnaturalizar o "inimigo" ou os "vencedores", permitindo que se tenha uma visão não monolítica sobre as pessoas, grupos, instituições, textos, espacialidades e temporalidades. A vida material e simbólica de Roma antiga, a poesia didática de Lucrécio e Manílio, os imaginários hagiográficos e as interações entre grupos aristocráticos e comunidades rurais... Temas diferentes, sem dúvida, mas cujas afinidades imergem na embatia objetiva da perspectiva historiográfica que tem o compromisso de (re)pensar constantemente as conexões aparentes ou fundamentais na articulação de diversos marcadores sociais.

A tarefa de "escovar a história a contrapelo", para usar mais uma expressão cara a Walter Benjamin (BEMVINDO, 2020; BENJAMIN, 1996, p. 225), é parte também da História Antiga e da História Medieval, tanto quando de uma da História da Cultura Material e Simbólica da arquitetura romana, de uma História das relações pedagógicas, ou mesmo uma História Cultural das imagens e imaginários hagiográficos acerca das relações entre animais e santos, ou de uma História Política e Materialista das interações entre aristocracia e campesinato. No combate às perspectivas simplistas, o dossiê é um convite e um mergulho no pensar historiográfico de como as elites antigas e medievais podem ser analisadas nas formas de dominação e regulação material, simbólica e política. Sem que 
façamos uma história dos vencedores, seja em um "presentismo utilitarista" ou em um "passado amorfo", como diriam Gabriel Torelly e Nilton Mullet Pereira (TORELLY; PEREIRA, 2014, p. 17), convidamos a todos e todas a navegar pelos meandros do pensamento crítico e historiográfico de tempos remotos só na aparência. Será um exercício de alteridade e identidade num só tempo.

O dossiê se encerra com uma entrevista concedida por mim a quatro mestrandos e uma mestranda do Laboratório de Estudos sobre a Transmissão e História Textual na Antiguidade e Medievo (LETHAM-UFBA) e do Programa de Pós-graduação em História da Universidade Federal da Bahia (PPGH-UFBA). Primeira iniciativa de um projeto de divulgação seriada de entrevistas por membros do LETHAM com professores e pesquisadores das áreas de História Antiga e Medieval, o debate é conduzido por Alan Rebouças Pereira, Beatriz Galrão Abrantes, Lucas Vieira de Melo Santos, Magide Jarallah Dracoulakis Nunes e Thiago Souza de Jesus. Na entrevista, são abordadas questões sobre o campo da História, da História Medieval e do Ensino de História, sobretudo as relacionadas com as contribuições e experiências do LETHAM para a produção do conhecimento crítico.

\section{REFERÊNCIAS}

BARROS, J. D’A.. Passagens de Antiguidade Romana ao Ocidente Medieval: leituras historiográficas de um período limítrofe. História, São Paulo, v. 28, n. 1, p. 547-573, 2009.

BASTOS, M. J. M. Quatro décadas de História Medieval no Brasil: contribuições à sua crítica. Dialogos, Maringá, v. 20, p. 3-15, 2016.

BASTOS, M. J. M.; RUST, L. D. Translatio Studii. A História Medieval no Brasil. Signum, São Paulo, v. 10, p. 163-188, 2008.

BEMVINDO, V. Escovar a história a contrapelo: contribuições de Walter Benjamin para a concepção dialética da história. Trabalho Necessário, v.18, n. 35, p. 20-37, jan.-abr., 2020.

BENJAMIN, W. Magia e Técnica, Arte e Politica: ensaios sobre literatura e história da cultura. São Paulo: Brasiliense, 1995.

CARVALHO, M. M. de; FUNARI, P. P. A. Apresentação do dossiê Os avanços da História Antiga no Brasil: algumas ponderações. História, São Paulo, v. 26, n. 1, p. 14-19, 2007.

LAVILLE, C. A guerra das narrativas: debates e ilusões em torno do ensino de História. Revista Brasileira de História, São Paulo, v. 19, n. 38, p. 125-138, 1999.

PEREIRA, N. M.; TORELLY, G. Ensino de História, Memória e fabulação. Aedos,. n. 14, v.6, jan./jul 2014. Disponível em: http://seer.ufrgs.br/index.php/aedos/article/view/41899. Acessado em: dez. 2020.

RIVERA GARRETAS, M.-M. La diferencia sexual en la Historia. València: Publicacions de la Universitat de València, 2005. 
SARTIN, G. O surgimento do conceito de "Antiguidade Tardia" e a encruzilhada da historiografia atual. Brathair, v. 9, n. 2, p. 15-40, 2009.

SILVA, A. C. L. F. Reflexões sobre o uso da categoria gênero nos estudos de História Medieval no Brasil. (1990-2003). Caderno Espaço Feminino, v. 11, n. 14, Jan./Jul., p. 87-107, 2004.

Marcelo Pereira Lima Professor de História Medieval da Universidade Federal da Babia (UFBA) Doutor em História pela Universidade Federal Fluminense (UFF) Pós-doutor pela Universidade de Salamanca

Coordenador do Laboratório de Estudos sobre a Transmissão e História Textual na Antiguidade e Medievo (LETHAM-UFBA) Editor da Revista Veredas da História 